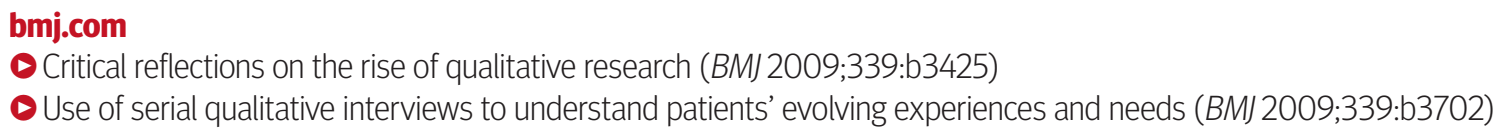

\title{
Qualitative methods: an alternative view
}

\section{John Paley and Richard Lilford argue that the idea that qualitative research is somehow different from quantitative research should not be allowed to diffuse into medical literature unopposed}

Qualitative research is undergoing a surge in popularity in the medical literature, as shown by the growth in the proportion of qualitative studies in the BMJ over the past two decades (figure). Though many qualitative studies are not obviously philosophical-for example, the authors might clinical targets-one school of thought claims that qualitative methods are derived from a constructivist philosophy. This view is widely accepted in several disciplines, including nursing. ${ }^{1-3}$ A recent series of papers published in the $B M J,^{4-9}$ designed to help readers to critically appraise qualitative research, devotes the whole of the first article to explaining the philosophical differences between qualitative and quantitative approaches. ${ }^{4}$ Kuper and colleagues state that the differences between qualitative and quantitative methods "run deeper than the presence and absence of numbers," and that "most qualitative researchers today share a different belief about knowledge, called 'constructivism,"' which is at odds with the "theoretical underpinnings" of quantitative methods. ${ }^{4}$ So what is constructivism, exactly?

\section{Constructivism}

The various descriptions of the constructivist philosophical framework share the view that "individuals create, negotiate, and interpret meanings for their actions and for the social situations in which they exist." "In most versions there is no such thing as an objective truth existing simply want to determine what doctors think of

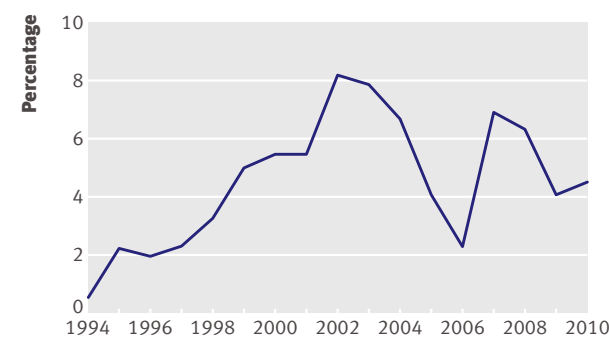

Year

Percentage of research in $B M$ J that is qualitative, 1994 to 3 September 2010. Data from bmj.com. No of qualitative papers found using the search term "qualitative," analysing each result to determine if it was a qualitative paper; expressed as percentage of total number of papers (all articles classified by the $B M J$ as "Research," excluding editorials, commentaries, corrections, etc)

outside or pre-existing the observer, objectivity is a "chimera," 10 and there are "multiple subjective realities," rather than a single objective one. Constructivism is contrasted with positivism, a philosophy that (according to constructivists) is the basis of quantitative research, including randomised controlled trials. The constructivist point of view is that positivism assumes an absolute truth, a single objective reality, and a detached, neutral standpoint from which this objective reality can be studied. Positivism is always portrayed as discredited.

Positivism and constructivism are said to be alternative paradigms, a term used to refer to the

\begin{tabular}{|c|c|c|}
\hline \multicolumn{3}{|c|}{ Basic beliefs attributed to positivism and constructivism } \\
\hline Belief & Positivism & Constructivism \\
\hline $\begin{array}{l}\text { Reality } \\
\text { (fragmentation versus holism) }\end{array}$ & $\begin{array}{l}\text { There is a single tangible reality, fragmented } \\
\text { into variables }\end{array}$ & $\begin{array}{l}\text { There are multiple constructed realities that can } \\
\text { be studied only holistically }\end{array}$ \\
\hline $\begin{array}{l}\text { Knowledge } \\
\text { (knower and known) }\end{array}$ & $\begin{array}{l}\text { The inquirer and the object of inquiry are } \\
\text { independent. A true, or approximately true, } \\
\text { understanding of the object is possible }\end{array}$ & $\begin{array}{l}\text { Knower and known are inseparable. There are } \\
\text { no independent, objective criteria by which the } \\
\text { truth can be achieved }\end{array}$ \\
\hline Generalisation & $\begin{array}{l}\text { The aim of inquiry is to develop context free } \\
\text { generalisations, which are true everywhere } \\
\text { and at all times }\end{array}$ & $\begin{array}{l}\text { Context free generalisation is not possible, but } \\
\text { findings are transferable on the basis of similarity } \\
\text { between the sample and future cases }\end{array}$ \\
\hline $\begin{array}{l}\text { Causation } \\
\text { (cause and meaning) }\end{array}$ & $\begin{array}{l}\text { Every action can be explained as the result } \\
\text { of a cause, and the effects of action can be } \\
\text { tested experimentally }\end{array}$ & $\begin{array}{l}\text { It is impossible to distinguish cause and effect. } \\
\text { Qualitative inquiry aims at understanding the so } \\
\text { called inside meanings of the actors concerned }\end{array}$ \\
\hline Values & $\begin{array}{l}\text { Inquiry is value free and can be guaranteed to } \\
\text { be so by the use of an objective methodology. } \\
\text { The inquirer aims at emotional detachment }\end{array}$ & $\begin{array}{l}\text { Inquiry is value bound. The personal values of } \\
\text { the inquirer must be consistent with the theory } \\
\text { and the method being used }\end{array}$ \\
\hline Method & $\begin{array}{l}\text { Inquiry is experimental and quantitative, and } \\
\text { aims at verification }\end{array}$ & $\begin{array}{l}\text { Inquiry is mainly qualitative and interpretive, } \\
\text { and aims at trustworthiness }\end{array}$ \\
\hline
\end{tabular}

Adapted from Lincoln and Guba. ${ }^{10-12}$ basic beliefs, or "axioms,"11 that dictate methodological preferences. The main contrasts between the constructivist and positivist paradigms (again, according to constructivists) are summarised in the table. This is adapted from the work of Lincoln and Guba (box), which has been enormously influential.

\section{Alternative views}

Lincoln and Guba, and those influenced by them, insist that positivists and constructivists have different basic beliefs on the nature of reality, knowledge, causation, and so on. But where do these beliefs come from? According to Lincoln and Guba, they are "arbitrary." They can be "assumed for any reason," and are "not selfevidently true." They "must be accepted at face value," and "cannot be tested for truthfulness against some external norm.” They "represent the ultimate benchmark against which everything else is tested." 1112 This arbitrariness entails that all methodological decisions, according to Lincoln and Guba, depend on the antecedent beliefs of the researcher. If the researchers reject the "single, tangible reality," and believe that objectivity is impossible, they are constructivists and should adopt interpretative methods. They need not provide any justification for their beliefs, because the beliefs can be "assumed for any reason," and "must be accepted at face value." There are no philosophical or empirical constraints on their selection of a paradigm. On this view, the validity of empirical inquiry always and inevitably depends not on evidence or argument, but on the arbitrary predilections of the researchers. It means that method is not accountable to anything other than personal preference. This cannot be right.

\section{Assessment of constructivist beliefs}

The individual "basic beliefs" that define the constructivist paradigm are also questionable. There is insufficient space to consider all, so we focus on three constructivist tenets that are often referred to, but are recycled without interrogation or sufficient scepticism.

\section{Fragmentation and holism}

The view attributed to positivism, that reality is fragmented into variables, is a straw man. No 
one believes it, and classification into types is something that all researchers, both quantitative and qualitative, do. Variables are a product of measurement procedures; they are not part of the structure of reality. In any case, the idea that anything can be studied holistically is debatable, since any description of the world must leave things out. Such is the case with models, the main vehicle of representation in science..$^{13}$ Models can be abstract (mathematical models), simulations (computer models), or physically realised (the DNA molecule, maps). The mechanisms identified can be physical (gases as collections of particles in constant random motion), psychological (health belief model), biological (natural selection), or sociological (Goffman's dramaturgical model of social action), among other possibilities. ${ }^{14}$

Paradoxically, models are useful because they omit things. A model represents only one aspect of the world, and the resources it uses are commensurate with that specific purpose. It makes no attempt to be global. The London Underground map, for example, represents the sequence of stations on different lines. It omits anything and everything else. It is not a comprehensive depiction of the network, let alone a holistic map of London. The map is intended to represent London from a limited perspective, and for a highly specific purpose: finding your way round the underground system. Likewise, the wave theory of light is useful when dealing with refraction, and the photon theory when designing solar energy panels. The same applies to descriptions of all kinds. Representation is intrinsically partial. ${ }^{13}$ It omits those features of reality that do not serve a specific purpose. It is not, and cannot be, holistic. This is precisely why a model, and every other form of description, is so informative. Holism, in any form of inquiry, is neither obtainable nor desirable.

\section{Knower and known}

The constructivist idea that the knower cannot be separated from the known implies that there are no independent criteria for determining

\footnotetext{
Lincoln and Guba, and Naturalistic Inquiry

Yvonne Lincoln and Egon Guba, two education researchers, are largely responsible for the widespread acceptance of the constructivist position in contemporary qualitative research. Their 1985 monograph, Naturalistic Inquiry, ${ }^{11}$ has attracted over 15000 citations (Google Scholar). Lincoln and Guba have been immensely influential in several social science disciplines, including nursing research. Their concepts-such as transferability and trustworthiness-are adopted by researchers who ostensibly use a wide range of qualitative approaches, including hermeneutics, ethnography, narrative inquiry, action research, grounded theory, and at least three distinct types of phenomenology.
}

whether a particular claim is true; and constructivists reject concepts such as validity, reliability, and objectivity out of hand. In general, they see objectivity as an "Enlightenment prescription," 10 predicated on the view that the world is "distinct from those who would know" it. For truth they substitute credibility, and propose that the test of qualitative research is resonance: "the extent that research findings have meaning for the reader."

What this view overlooks is that human beings are apt to succumb to cognitive illusions. People have a striking propensity to misconstrue data, ${ }^{15}$ and to discount information that contradicts antecedent beliefs. The history of objectivity is a history of spotting various ways in which we get things wrong ${ }^{16}$ and devising measures for reducing the risk that we will do so. ${ }^{17}$ It is the problem of fallibility, the perpetual danger of succumbing to error, that drives the concept of objectivity, not an Enlightenment prejudice. To dismiss this history, and to suggest that there are no independent criteria for distinguishing between how it is and how it seems, is to imply that nothing can be done to reduce the risk of being mistaken, deceived, or led astray. Objectivity is a corrective strategy. It is not a philosophical preference or an instrument of authority.

As for resonance, it is a poor test of whether findings are valid (that is, worthy of being acted on). Many things have resonance, even if they are false, misleading, or expressions of wishful thinking. The real test of a research study is not the extent to which it confirms the reader's preconceptions, but the extent to which the evidence confirms or disconfirms a theory.

\section{Cause versus meaning}

Despite its centrality to constructivism, the concept of meaning is rarely scrutinised. It is largely taken for granted and meanings are assumed to be transparent. However, an extensive social psychology literature suggests the opposite. In particular, mental states-motives, desires, and beliefs-are often opaque to the person experiencing them. ${ }^{18}$ Individuals are not necessarily a reliable guide to their own preferences, reasons for action, views, and opinions. This opacity applies even to the immediate contents of experience, which can be indeterminate; and the brain typically compensates for this indeterminacy, preconsciously, by fabricating both sensory data and psychological states. ${ }^{19}$ People's accounts of their decisions, including when and how they make them, are equally unreliable. The sense of personal identity is no more secure, but the brain creates fictions in order to maintain the illusion that there is a unified agent operating in a meaningful world..$^{20}$ Similarly, we confabulate past events, past intentions, and past motives in order to compensate for the gaps with which memory is riddled. ${ }^{2122} \mathrm{We}$ are, to a considerable

\section{PHILOSOPHICAL BASIS OF RESEARCH}

- Qualitative research is often described as a paradigm in which the objective is to determine meanings, and trace the way in which they are created, negotiated, and interpreted.

- The social psychology literature indicates that access to meaning is deeply problematic and failure to separate the knower from the known is fraught with inferential risk.

- There is no philosophical basis for shoe horning scientific methods into paradigms in the form of immutable packages of beliefs about the nature of knowledge and reality.

- Models, the primary form of representation in science as in any form of inquiry, depict a single aspect of the world and propose an explanation forit.

- No form of description can be holistic.

- There is no philosophical difference between qualitative and quantitative studies, both of which must employ models and measurement to represent the world.

degree, "strangers to ourselves." ${ }^{18}$ Any approach to qualitative research that takes no account of these findings, and that treats the meanings reported by respondents as authoritative, must be regarded with suspicion. It is impossible, without further inquiry, to rely on what people say about themselves, their experience, or their interpretations of what has happened to them.

\section{Qualitative method}

In our view, it is neither necessary nor desirable that qualitative research should align itself with a particular philosophy. We do not accept the claim that the quantitative/qualitative distinction runs "deeper than the presence or absence of numbers." ${ }^{4}$ Qualitative and quantitative methods are only alternative tools, used for different tasks in research (as saws and screwdrivers are alternative tools used for different tasks in carpentry). They have no philosophical implications. They are fit for purpose in a variety of situations. Pursuing this line of thought, we will close with a few brief notes on the alternative to constructivism.

Words and numbers should be conceived as alternative forms of measurement. ${ }^{23}$ They are both outputs of a causal interaction between the world and an instrument, whether it be a thermometer, a weighing scale, or a series of unconstrained interview questions. Just as a thermometer measures temperature using a calibrated numerical scale, so an interview measures experience, beliefs, and attitudes using a calibrated linguistic scale. In the qualitative case, the scale comprises the sentences of a language, capable of discriminating between one belief, or one experience, and another. This view accommodates the idea that no one has privileged access to his or her mental states, or to their meanings. Self report data are just that: first person data for analysis by the researcher. ${ }^{19}$ 
Words and numbers are also among the resources than can be used to devise models. Numbers are incorporated in mathematical models governing the behaviour of a system (although the system is itself a model abstracted from a complex physical reality). Similarly, words are incorporated in psychological, social, and organisational models, explaining the behaviour of a person, social group, or institution. Such models can be derived from first person data, but they are not restricted to representing people's view of themselves.

Any particular model can explain only one facet of the behaviour of an individual, population, or system. It represents just one slice through the cake. Constructivist methodologists describe this focus on specific aspects of the world as reductionist, a term they apply to quantitative research in general. However, the implied alternative-the representation of a phenomenon in all its complexity-is neither possible nor desirable. Just as a map is useful because it excludes extraneous material, so a model is useful because it does not attempt to depict everything. ${ }^{13}$

If the distinction between quantitative and qualitative research is no longer a difference between paradigms, then the claim that concepts such as validity, truth, and objectivity are not applicable to qualitative methods is vitiated. The minimalist position will be that all forms of investigation should incorporate procedures designed to reduce the risk of inferential error. In quantitative studies, this is achieved by, for example, experimental pro- tocols and the error statistical canon. ${ }^{17}$ In qualitative studies, there is no canonical equivalent; but there are procedures with a comparable function, such as interobserver reliability, theoretical sampling, and discouraging clinicians from researching their own patients. All these procedures resist the view that the credibility of research findings has something to do with the resonance they create in the reader. ${ }^{9}$

The development of mixed methods research should be welcomed (and is a symptom of the breakdown of paradigm thinking) even if many authors think that it involves the turpitude of "combining paradigms," because "qualitative research emphasises an inductive-subjective-contextual approach and quantitative research emphasises a deductive-objective-generalising approach." ${ }^{5}$ This contrast is, in our view, both unnecessary and incorrect. Bayesian methods, for example, are quantitative and generalising but also inductive, subjective, and contextual. ${ }^{24}$

\section{Conclusion}

Some readers may argue that what we have outlined is just another positivist version of qualitative research. The objection makes sense only if the Lincoln and Guba account of paradigms is presupposed; and this is precisely the framework we reject. We do accept the distinction between good fit and bad fit, between how it is and how it seems; but that is a distinction to which every researcher should be committed. Other readers may think that the constructivist paradigm is so implausible as not to require any attempt at refutation. However, it cannot be assumed that an idea that has become mainstream in other disciplines will not gain ground in medicine. We offer our argument in order that it should not do so unopposed.

John Paley senior lecturer, School of Nursing, Midwifery and Health, University of Stirling, Stirling, UK

Richard Lilford professor of clinical epidemiology, Public Health Epidemiology and Biostatistics, University of Birmingham,

Edgbaston, Birmingham, West Midlands B152TT, UK Correspondence to: R Lilford r.j.lilford@bham.ac.uk

Accepted:20 December 2010

We thank Jon Nicholl and Mark Risjord for helpful comments and Peter Chilton for preparing versions of the manuscript and for tracking references.

Contributors and sources: RL is a clinical epidemiologist with an interest in research methods and healthcare economics.JP is a philosopher who writes about research methods, epistemology, and ethics in healthcare. JP was responsible for the conception of the article.JP and RL developed the ideas, and JP wrote the first draft.JP and RL subsequently reworked content and structure, and both contributed to successive drafts.JP is guarantor.

Competing interests: All authors have completed the unified competing interest form at www.icmje.org/coi_disclosure.pdf (available on request from the corresponding author) and declare that RL had financial support from the National Institute for Health Research (NIHR) Collaborations for Leadership in Applied Health Research and Care (CLAHRC) for Birmingham and Black Country, although views expressed are his own; they had no financial relationships with any organisations that might have an interest in the submitted work in the previous three years; no other relationships or activities that could appear to have influenced the submitted work

Provenance and peer review: Not commissioned; externally peer reviewed.

References can be found on bmj.com.

Cite this as: BMJ 2011;342:d424

\section{ANSWERS TO ENDGAMES, p 983. For long answers go to the Education channel on bmj.com}

\section{PICTURE QUIZ An unusual cause of stroke and hypoxia}

1 The chest radiograph shows a large soft tissue opacity projected over the right heart border, suggestive of a pulmonary arteriovenous malformation (fig 1). The computed tomography pulmonary angiograph confirms the presence of a pulmonary arteriovenous malformation in the right middle lobe (fig 2).

2 A pulmonary arteriovenous malformation can be associated with the clinical features of hypoxaemia, such as cyanosis and clubbing, because of arteriovenous shunting of deoxygenated blood and with increased risk of stroke and cerebral abscess owing to venous emboli passing into the arterial circulation.

3 The likely underlying condition is hereditary haemorrhagic telangiectasia, also known as Osler-Weber-Rendu syndrome.

4 Hereditary haemorrhagic telangiectasia is caused by mutations in genes that encode components of the TGF- $\beta$ superfamily signalling pathways; however, it appears that a stimulus such as angiogenesis is required to make these mutations deleterious. Hereditary haemorrhagic telangiectasia has an autosomal dominant pattern of inheritance and manifests as a heterozygous condition; therefore, children with one affected parent have a $50 \%$ chance of being affected. Clinical manifestations may vary within families because of the variable genetic penetrance of the disease.

5 The Curaçao criteria are currently the mainstay of clinical diagnosis of hereditary haemorrhagic telangiectasia. Management involves screening for and treatment of arteriovenous malformations in the patient and related individuals. Genetic testing is also available.

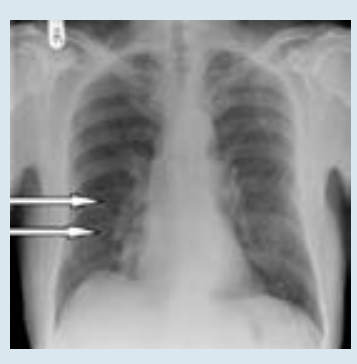

Fig $1 \mid$ Chest radiograph showing a large soft tissue opacity projected over the right heart border (arrows)

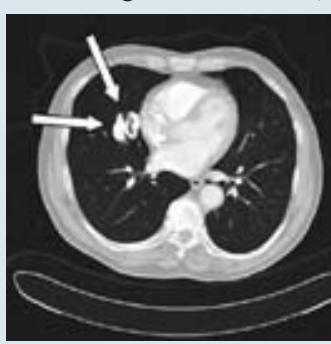

Fig 2 |Computed tomography pulmonary angiograph showing a pulmonary arteriovenous malformation in the right middle lobe (arrows)
STATISTICAL QUESTION

Number needed to treat I

Answer $d$ is the best description.

ON EXAMINATION QUIZ

Pseudoseizures

Answer $B$ is correct. 